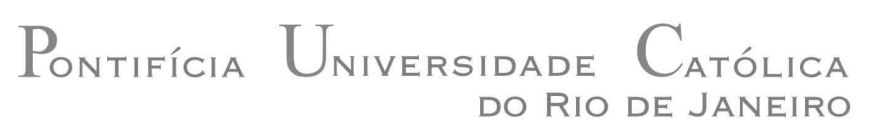

Marcelo Vianna Lacerda de Almeida

\title{
A eficiência do signo empresarial e as estratégias de legitimação do campo do design
}

Dissertação de Mestrado

Dissertação apresentada ao Programa de PósGraduação em Design do Departamento de Artes \& Design do Centro de Teologia e Ciências Humanas da PUC-Rio como requisito parcial para obtenção do título de Mestre em Design

Orientador: Prof. Alberto Cipiniuk 
Marcelo Vianna Lacerda de Almeida

\title{
A eficiência do signo empresarial e as estratégias de legitimação do campo do design
}

\begin{abstract}
Dissertação apresentada como requisito parcial para obtenção do grau de Mestre pelo Programa de PósGraduação em Design do Departamento de Artes e Design do Centro de Teologia e Ciências Humanas da PUC-Rio. Aprovado pela Comissão Examinadora abaixo assinada
\end{abstract}

Prof. Alberto Cipiniuk

Orientador

Departamento de Artes \& Design - PUC-Rio

Prof. Everardo Rocha

Departamento de Comunicação - PUC-Rio

Prof. Washington Dias Lessa

Escola Superior de Desenho Industrial - UERJ

Paulo Fernando Carneiro de Andrade Coordenador Setorial do Centro de Teologia

e Ciências Humanas - PUC-Rio

Rio de Janeiro, 10 de abril de 2006 
Todos os direitos reservados. É proibida a reprodução total ou parcial do trabalho sem autorização da universidade, do autor e do orientador.

\section{Marcelo Vianna Lacerda de Almeida.}

Graduou-se em Design na Escola Superior de Desenho Industrial da Universidade do Estado do Rio de Janeiro em 1986. É designer gráfico e desenvolve signos visuais para diversas empresas.

Ficha Catalográfica

Almeida, Marcelo Vianna Lacerda de

A eficiência do signo empresarial e as estratégias de legitimação do campo do design / Marcelo Vianna Lacerda de Almeida; orientador: Alberto Cipiniuk. - Rio de Janeiro: PUC, Departamento de Artes e Design, 2006.

127 f. : il. ; $30 \mathrm{~cm}$.

Dissertação (mestrado) - Pontifícia Universidade Católica do Rio de Janeiro, Departamento de Artes e Design.

Inclui referências bibliográficas.

1. Artes - Teses. 2. Logotipo. 3. Signo empresarial. 4. Imagem. 5. Estrutura do campo do design. 6. Legitimação do signo empresarial. I. Cipiniuk, Alberto. II. Pontifícia Universidade Católica do Rio de Janeiro. Departamento de Artes e Design. III. Título. 
Para meus pais, Lygia e Amaury, pelo constante apoio e confiança

ao Dr. Jaderson, in memoriam, pelo carinho e lições de vida. 


\section{Agradecimentos}

A Deus pela força em todos os momentos.

Ao meu orientador Professor Alberto Cipiniuk pelo estímulo, parceria e extraordinária visão de mundo necessários à realização do trabalho.

À Confederação Nacional do Comércio que proporcionou a oportunidade e a disponibilidade de tempo para execução da pesquisa.

Aos meus pais pelo ensino da persistência para o alcance de qualquer objetivo.

Aos professores que participaram da Comissão examinadora.

Aos professores Gustavo Bomfim (in memoriam) e Denise Portinari, do Laboratório da Representação Sensível, pelo apoio e os ensinamentos relevantes à pesquisa.

À Cristina Garcia pela ajuda e acompanhamento das questões do processo de pesquisa.

Aos amigos do Centrovida, pelo apoio no processo de realização do trabalho.

À Anna Maria Castro Santos, pela revisão e sugestões que enriqueceram o entendimento do conteúdo.

Aos meus colegas do Departamento de Artes e Design da PUC-Rio.

A todos amigos e familiares que prestaram ajuda em diversos momentos do trabalho.

Aos professores e funcionários do Departamento de Artes e Design da PUC-Rio. 


\section{Resumo}

Almeida, Marcelo Vianna Lacerda de; Cipiniuk, Alberto. A eficiência do signo empresarial e as estratégias de legitimação do campo do design. Rio de Janeiro, 2006. 127 f. Dissertação de Mestrado - Departamento de Artes e Design, Pontifícia Universidade Católica do Rio de Janeiro.

Ao se olhar para o logotipo ou o símbolo gráfico - signo empresarial - de um empreendimento qualquer, sempre surgem interrogações. Seja o signo ainda desconhecido, seja ele familiar, há de se perguntar o que esta forma está por representar ou o que a levou a ser escolhida, para que continue a representar a empresa a que se refere. Em ambos os casos, o que inspira o questionamento é: o que faz um signo visual ser eficiente? Desde que a marca assumiu uma importância indiscutível no mundo empresarial, se discute a força que a representação gráfica da empresa exerce, possibilitando identificar o negócio e realizar o incremento das vendas dos produtos a ela associados. O propósito deste trabalho é apresentar o entendimento de como um signo empresarial atinge esta eficiência, fazendo-nos compreender que isto não está na sua configuração, mas lhe é conferido a partir de um campo simbólico de produção - o campo do design. São aqui considerados W.J.T. Mitchell, autor que contempla aspectos do funcionamento de uma imagem, e fundamentalmente, Pierre Bourdieu, que explicita, por meio da teoria de produção em campos simbólicos, a maneira pela qual um bem simbólico - uma imagem - alcança o reconhecimento como legítimo. A partir desta articulação, é possível compreender que a eficiência do signo empresarial depende de uma legitimação, produzida nas relações entre as diversas instâncias desse campo autônomo do design; ao contrário da crença dos designers.

\section{Palavras-chave}

Logotipo, signo empresarial, imagem, eficiência, estrutura do campo do design, legitimação do signo empresarial. 


\section{Abstract}

Almeida, Marcelo Vianna Lacerda de; Cipiniuk, Alberto (Advisor). The efficiency of business signs and strategies for legitimacy in the design field. Rio de Janeiro, 2006. 127 p. MSc. Dissertation - Departamento de Artes e Design, Pontifícia Universidade Católica do Rio de Janeiro.

When looking at the logo or the graphic symbol - business sign - of any enterprise, questions always arise. Whether the sign is still unknown or whether it is familiar, one will ask what this shape represents or what led it to be chosen, so that it could continue to represent the company to which it refers. In both cases, what inspires the questioning is: what makes a visual sign efficient? Since the brand name took on indisputable importance in the business world, there has been discussion of the force exerted by a company's graphic representation, which makes it possible to identify the business and promote increased sales of the products associated with it. The purpose of this work is to present an interpretation of how a business sign attains this efficiency, knowing that this does not derive from its shape alone, but is conferred upon it based on a symbolic field of production - the field of design. Following in the footsteps of W.J.T. Mitchell, an author who has addressed aspects of an image's functioning and, fundamentally, Pierre Bourdieu, who has made clear, by means of the theory of production in symbolic fields, the way in which a symbolic asset - an image achieves recognition as legitimate, it is possible to understand that the efficiency of a business sign depends on legitimacy, which is produced in the relations between the various levels of this autonomous field of design, contrary to the designers' belief.

\section{Key Words}

Logo, business sign, image, efficiency, design field structure, legitimacy of business signs. 


\section{Sumário}

1. Introdução

2. A ocorrência das marcas e o olhar em sua direção 18

2.1. As origens das marcas e de suas representações gráficas

2.2. Definições dos signos visuais - representações gráficas das marcas - e as categorias utilizadas pelos designers

2.3. O que é simbólico no signo empresarial

3. O signo empresarial é uma imagem

3.1. O poder de transmissão da imagem

3.1.1. A produção de conhecimento pela imagem 43

3.2. O olhar individual e coletivo

3.2.1. Uma introdução à eficiência do signo empresarial

4. A eficiência predita do signo - crença e discurso no meio profissional

4.1. O discurso dos designers e as qualidades atribuídas ao signo em um projeto

4.1.1. As qualidades atribuídas no interior dos discursos

4.1.2. Alguns comentários

4.2. A construção do campo do design, suas origens e o seu ensino 80

4.2.1. A formação do campo do design

4.3. Haveria competência dos designers em planejar signos? 
5. A estruturação do campo em Pierre Bourdieu - questões gerais relativas à produção e ao valor do bem simbólico

5.1. Introdução à relação entre a eficiência do signo e a estrutura

5.2. A estruturação do campo do design e a produção do signo empresarial

5.3. A circularidade do campo - Questões de legitimação e consagração

5.4. A eficiência do signo empresarial e a condução do processo de legitimação 105

5.4.1. Como o processo se realiza 106

6. Conclusão 120

7. Referências bibliográficas 


\section{Lista de ilustrações}

Figura 1 - Página de artigo do periódico Industrial Design 22

Figura 2 - Diversos símbolos existentes em forma de elipse, coletados na Internet

Figura 3 - Antigo e novo logotipos do periódico Sexy e o respectivo anúncio dessa mudança no mesmo periódico

Figura 4 - Página dupla de artigo do periódico Design gráfico

Figura 5 - Peça de divulgação por e-mail de evento - apresentação case Claro - da 7ํㅡㄹienal de Design Gráfico

Figura 6 - Peça de divulgação por e-mail de lançamento de livro e DVD sobre Alexandre Wollner

Figura 7 - Anúncio de página inteira da empresa Chevron, no jornal $O$ Globo 
Tudo o que fazemos está localizado em estruturas sociais e, portanto, é afetado por elas. [...] é a existência dessas estruturas e instituições que nos permite toda e qualquer atividade, e isso se aplica igualmente a atos de conformidade, a atos de rebelião.

Janet Wolff, A produção social da arte 